Bury forever that old Latin word cancellation.

"Sometimes it means to add and sometimes it means to divide. How do you know?" said a little freshman.

Put into the same grave also that omnibus misnomer old "simplify," meaning everything and nothing. Say plainly and constantly "multiply, divide, add, or subtract" and oblige your pupils to do the same. Then, when memory has served its purpose, when facts fail the youngsters, and reason is seeking her own there will remain only the work fit for reason, that is to find out when to add, when to multiply, and so on.

Much would be the gain in our school mathematics. Much the gain in honest speech which scorns the false and meaningless. Much the gain in the pupil's ability to find himself when lost in an algebraic maze, without the aid of the prompting teacher who should at this time be most properly "cancelled out" of the expression; thus allowing our pupil the pleasure and profit of independent school effort as a slight preparation for the world's equation which he must solve alone.

\title{
COLORED CRAYONS AS AN AID IN TEACHING MATHEMATICS.
}

\author{
By Ada M. Parsons, \\ Milwaukee West Division High School.
}

In teaching geometry, one of the articles in the "first aid to the weak" box of devices should be a few colored crayons. A great variety is unnecessary; but a few that show clearly on the blackboard are of assistance in illuminating the darkness in which some minds seem to grope when a lesson in geometry is under discussion.

The use of these crayons is varied, and new applications suggest themselves each year-some to be rejected because they involve too complicated elaborations, and others to be kept in mind ready for the emergencies which they fit.

One of the first applications comes in the theorems proving the congruity of two triangles by making them coincide. If each part of one triangle is colored when it has been definitely proved that the corresponding part of the other has been made to coincide with it, fewer pupils will make one line fall upon another because "the two lines are equal," and various other steps are made clearer. 
In the application of the propositions concerning congruity of triangles to succeeding propositions and to originals, giving the same color to the lines or angles which are known to be equal enables the beginner to see which combination he has and whether or not it is sufficient for his purpose. For instance, in the proposition, "The angles opposite the equal sides of an isosceles triangle are equal," the two legs might be colored blue, the construction line bisecting the vertex angle yellow, and the halves of the vertex angle red. Result-the eye sees the two sides and the included angle in each triangle. After this the selection of homologous parts as those opposite like colored sides or angles is a comparatively simple matter, even if the triangles are not arranged in similar positions on the page or board.

The distinction between a theorem and its converse may be shown vividly by coloring each figure with one color for the hypothesis and another for the conclusion. Thus in the theorem previously quoted and its converse, if it is agreed that the parts which are given equal by hypothesis are to be colored blue while those of the conclusion are red, in the one case there will be shown the blue legs and the red angles at the base, while in the other figure the colors will be reversed.

In working with locus problems our colored crayons are invaluable. If the student learns at first to put in the locus in color, it gives definiteness to his otherwise hazy idea of the use of the word. In a problem whose solution demands the intersection of two loci he sees that every point in the blue locus satisfies certain of the conditions, and that every point in the red locus satisfies other conditions. A point, therefore, which is both blue and red must satisfy all the conditions under which the two loci were constructed.

There is a wide divergence of opinion as to the advisability of introducing the pupil to the dread "theory of limits" in his high school course in geometry. Many of us believe that there is enough of value in it for our pupils to warrant our spending a little time on it. Colored crayons are of great assistance here, for instance, in the demonstration of the theorem "Two circumferences have the same ratio as their radii." After the preliminary work has been done, and variables have been created by the magic words, "Continuously double the number of sides of the inscribed polygons," the letters which represent variables are put down in color, while the constants are white. The fact that the ratio $\mathrm{P}: \mathrm{R}$ is a variable is emphasized by drawing a colored 
ring about it, thus enabling the student to find that "the two variables which, are always equal" are ratios, and that as a result of their equality the two constant limiting ratios are equal.

These are a few of the ways of using colored crayons in geometry. In algebra their application is more limited, but occasionally they are of use here. An instance of this is in the solution of literal equations, especially where some letter other than $x$ represents the variable. If the variable appears in a colored costume, there is less danger of a solution in which it appears in the result.

All these, of course, are devices by means of which the pupil's imagination may be quickened so that he may learn to work without any such aids to the eye. They also serve as a quick test of his mastery of these points. Frequently when the crayons are placed in his hands he shows by his use of them that he thoroughly understands a demonstration, or else he enables the teacher to see exactly where his difficulty lies.

When the colored crayons are brought out, the bright student looks up with interest to see what new use is to be made of them, and the slow one is alert in the hope, often fulfilled, that the way will be made clearer to him, so that he may take another step forward in the mastery of the subject.

\section{LITTLE COAL AND OIL DEVELOPMENT IN ALASKA.}

Alaska coal fields continue to be undeveloped, according to the United States Geological Survey. The only coal being mined is some lignite coal taken out for local use at Cook Inlet, on Seward Peninsula, and at several other localities. The total production in 1912 did not exceed 100 or 200 tons.

One oil company continued operations in the Katalla petroleum field in 1912 , as in 1911. One of the two producing wells is said to have been sunk to a depth of about 800 feet. The oil is procured by pumping and is refined in a small plant located near Katalla, and the gasoline finds a ready sale in the coastal setttlements of this part of Alaska. There are several other oil companies which control property in this field, but these seem to have done little in the way of development during 1912. 